\author{
Safaa N.H. Al-Hussaini \\ Environmental Engineering \\ Department, Al-Mustansiriyah \\ University, Baghdad, Iraq. \\ eng.safa74@yahoo.com
}

\section{Eman A. Mohammed \\ Environmental Engineering Department, Al-Mustansiriyah University, Baghdad, Iraq.}

\section{Abdul Hameed M.J. Al- Obaidy}

Environmental Research Center, University of Technology, Baghdad, Iraq. 10929@uotechnology.edu.iq

Received on: $30 / 09 / 2018$ Accepted on: 21/05/2019 Published online: 25/05/2019

\title{
Removal of Reactive Red Dye (Cibacron FN-R) from Synthetic Wastewater by Using Natural Substance
}

\begin{abstract}
Synthetic textile wastewater was simulated by using Cibacron reactive red dye FN-R. Pomegranate peels were used as adsorbents to remove the red dye by applying a continuous fixed bed column reactor system having a filter with a diameter of $30 \mathrm{~mm}$ and a length of $110 \mathrm{~mm}$. The effect of different parameters on the removal efficiency was studied; pH levels (2, 4, 6, 8, 10, and 12), flow rate $(27,45$, and $60 \mathrm{ml} / \mathrm{min})$, initial dye concentration $(10,15,20$, and $25 \mathrm{mg} / \mathrm{l})$, and the contact time (30, 60, $90,120,150$, and $180 \mathrm{~min})$. It was found that the optimum $\mathrm{pH}$ level was within the range of 6 to 6.5. In addition, the removal efficiency was found to increase with decreasing the flow rate and the initial concentration of dye and increasing the contact time. The maximum percentage removal of dye obtained was $90 \%$ at $\mathrm{pH}$, flow rate, initial concentration of dye, and the contact time equal to $6,27 \mathrm{ml} / \mathrm{min}, 10 \mathrm{mg} / \mathrm{l}$, and $180 \mathrm{~min}$ respectively.

Langmuir and Freundlich isotherm models were applied. The following equations were found for Langmuir and Freundlich respectively; $Y=0.017 X+1.110$ and $Y=0.810 X+0.083$. The corresponding correlation coefficients were 0.961 and 0.994 , respectively, indicating that the Freundlich isotherm model being more representing to the data obtained in this study.
\end{abstract}

Keywords- Reactive red dye, Pomegranate peels, Continuous flow reactor, Adsorption.

How to cite this article: S.N.H. Al-Hussaini, E.A. Mohammed and A.H. Al-Obaidy "Removal of Reactive Red dye (Cibacron FN-R) by Using Natural Substance," Engineering and Technology Journal, Vol. 37, Part C, No. 2, pp. 209-213, 2019.

\section{Introduction}

Water pollution is a major problem facing the planet earth with all of its living beings. During the years, the disposals of all types of wastewater have been discharged into rivers and surface waters. If not treated properly, the released wastewater into rivers may add undesirable properties to the water quality and the aquatic life of rivers [1]. An example of the types of wastewater is dye-consuming industries such as paper, plastics, textiles and others. The textile industry produces wastewater that is nonbiodegradable, heavily toxic and has high concentrations of dyes [2]. Due to the properties of the synthetic organic compounds of dye, difficulties of its treatment occurs [3]. Several types of organic dyes' treatments were studied, having the adsorption being one of the most common ways $[4,5,6,7]$. A wide variety of adsorbents can be used in the process of dye treatment by adsorption such as biomass, zeolites, polymers, agricultural ravage, industrial byproducts, and others [8]. Recently, organic nanocomposites were studied as adsorbents [9].
Pomegranate trees are small in size (5 to $8 \mathrm{~m}$ height); they are available at several parts of the world. Many parts of this tree have been used as a cure for diseases (seeds, leaves, flowers, fruits, and others) [10]. Pomegranate peels are an inexpensive by-product of its fruit. For that reason, it was used by many researchers as an adsorbent to remove different types of wastes $[11,12,13,14]$.

This study is concerned in using pomegranate peels as an adsorbent to remove the Cibacron reactive Red FN-R dye throughout a continuous fixed bed column reactor system. Different parameters were observed with regard to the removal rate; such as initial dye concentration, $\mathrm{pH}$ levels, and the flow rate.

\section{Experimental Set-up and Materials}

\section{Materials}

DOI: https://doi.org/10.30684/etj.37.2C.2

2412-0758/University of Technology-Iraq, Baghdad, Iraq

This is an open access article under the CC BY 4.0 license http://creativecommons.org/licenses/by/4.0 
The wastewater used in this study was synthetic; it was prepared at different dye concentrations using Cibacron reactive Red FN-R dye with a color index number of CI Reactive Red 238 and a chemical formula of $\mathrm{C}_{29} \mathrm{H}_{15} \mathrm{O}_{13} \mathrm{~S}_{4} \mathrm{ClFN}_{7} \mathrm{Na}_{4}$. The Cibacron red reactive dye had been supplied from AL-Kut textile factory south of Baghdad, (Department of Dying and Printing).

$\mathrm{H}_{2} \mathrm{SO}_{4}$ acid and $\mathrm{NaOH}$ bass were used to obtain different $\mathrm{pH}$ levels.

Pomegranate peels were collected, dried, submerged for 24 hours in hydrochloric acid, rinsed with distilled water for a few times then dried at $50^{\circ} \mathrm{C}$ for one day. Afterwards, Pomegranate peels were grinded, and sieved to be used as the adsorbent.

\section{Experimental set-up}

The continuous fixed bed column reactor system used in this study was built manually. Continuous flow was provided by means of steady head $8 \mathrm{~L}$ upper tank connected to the $3 \mathrm{~cm}$ diameter cylindrical column which had a total height of 11 $\mathrm{cm}$. Valves were used to control in and out flow from the reactor. Figure 1 shows the experimental setup, while Figure 2 illustrates a sketch of the system.

Several sets of experiments were conducted. In each experiment, only one parameter was variable and all of the other parameters were fixed in order to cover all of the effecting variables on the dye removal efficiency.

The effects of $\mathrm{pH}$, flow rate (Q), initial concentration of dye $\left(\mathrm{C}_{\mathrm{o}}\right)$, and contact time $(\mathrm{t})$ on the decolorization efficiency were studied. The depth of the bed adsorbent was fixed on $8 \mathrm{~cm}$. Six $\mathrm{pH}$ values $(2,4,6,8,10$, and 12) were considered. Three flow rates $(27,45$, and 60 $\mathrm{L} / \mathrm{min}$ ) were investigated. Four initial dye concentrations $(10,15,20$, and $25 \mathrm{mg} / \mathrm{L})$ were examined. For each experiment, six effluent samples were taken (a sample per half an hour for three hours) and one influent sample representing the raw wastewater. The stopwatch volume method was used to measure the influent and effluent discharges from the column.

\section{Results and Discussion}

\section{The effect of $\mathrm{pH}$ level}

The $\mathrm{pH}$ level has a direct effect on the decolorization process by adsorption. For that, it was the first set being studied in this research. The initial concentration of dye and the flow rate were fixed on $25 \mathrm{mg} / \mathrm{L}$ and $27 \mathrm{ml} / \mathrm{min}$, respectively, while the $\mathrm{pH}$ levels ranged from 2 to 12.
Figure 3 shows the relation between different $\mathrm{pH}$ levels and the percentage removal efficiency of dye. The removal efficiency was calculated according to equation number (1).

$\% R=\frac{C_{o}-C}{C_{o}} * 100 \%$

Where: $\mathrm{C}_{\mathrm{o}}$ and $\mathrm{C}$ are the initial and final concentrations of dye, respectively, and $\% \mathrm{R}$ is the removal efficiency.

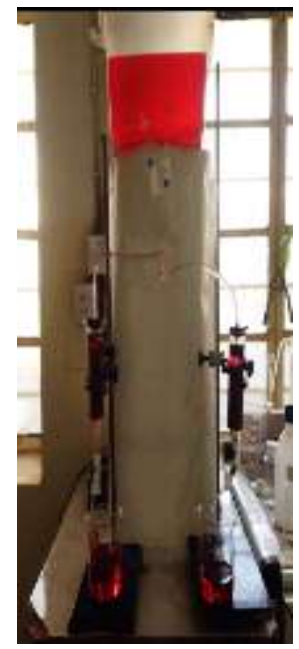

Figure 1: The exp. setup

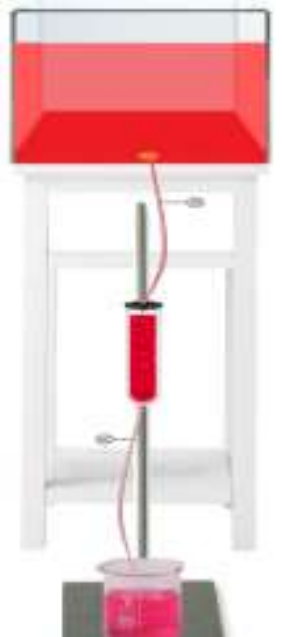

Figure 2: Sketch of exp. setup

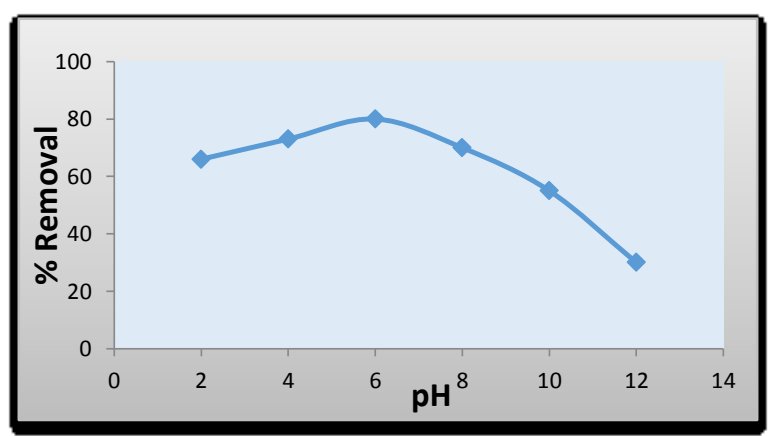

Figure 3: The effect of $\mathrm{pH}$ on the removal of reactive red dye

The $\mathrm{pH}$ point of zero charges $\left(\mathrm{pH}_{p z c}\right)$ for pomegranate peels was found to be 6.35 [15]. The surface of the adsorbent would have a positive 
charge at $\mathrm{pH}$ levels lower than the $\mathrm{pH}_{p z c}$ (6.35 for this case) while negative charges occur at higher $\mathrm{pH}$ levels. The dye molecule has a negative charge, which leads to electrostatic interaction between the adsorbent surface and the dye molecule, eventually resulting in higher removal efficiency of dye. As shown in Figure 3, the optimum $\mathrm{pH}$ level corresponding to the highest rate of removal of dye $(\% \mathrm{R}=80)$ was 6 (lower than the $\mathrm{pH}_{p z c}$ of pomegranate 6.35). On behalf of that, the $\mathrm{pH}$ level was fixed on 6 for further experiments.

\section{The effect of flow rate}

Since the reactor was a continuous flow column, the effect of different flow rates $(27,45$ and 60 $\mathrm{ml} / \mathrm{min}$ ) on the removal of dye was studied in this set of experiments. The $\mathrm{pH}$ level, initial concentration of dye, and the height of adsorbent in the filter were fixed as $6,10 \mathrm{mg} / 1$, and $8 \mathrm{~cm}$ respectively. Figure 4 depicts the effect of different flow rates on the removal of red dye. From this figure, it can be seen that the removal efficiency was increased with time for all three-flow rates taken; the maximum percentage removal $(90 \%)$ was depicted at the lowest flow rate $(27 \mathrm{ml} / \mathrm{min})$. This can be explained as follows; the longer the time is and the lower the flow rate, this gives a longer contact time between the wastewater, representing the adsorbate, and the pomegranate peel, representing the adsorbent, allowing large quantities of dye to be adsorbed on the media surface. It should be mentioned that the break through point was not reached during the experiments due to technical reasons for prolonged operation inside the laboratory.

\section{Effect of initial dye Concentration}

This set of experiments included testing the removal of four initial dye concentrations $(10,15$, 20 , and $25 \mathrm{mg} / \mathrm{l}$ ) by the media. Figure 5 illustrates the relation between the percentage removals with time for different initial dye concentrations.

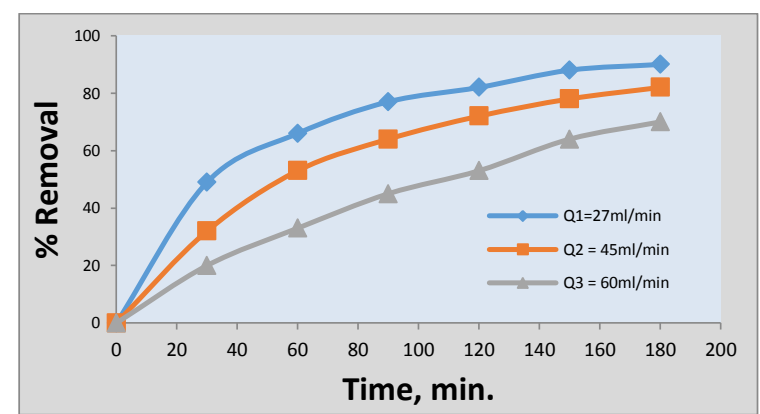

Figure 4: The effect of the flow rate on the removal of dye

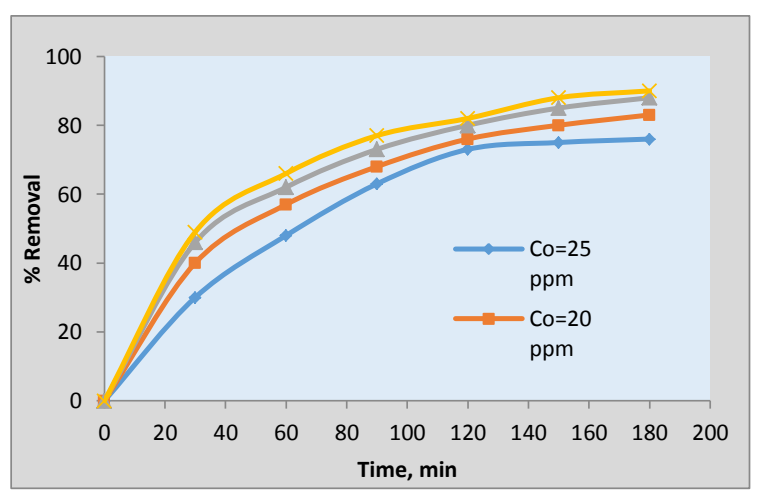

Figure 5: The effect of initial dye concentrations on the \% removal of dye

Figure 4 shows that the percentage removal of dye by pomegranate peels increase from $76 \%$ for the initial dye concentration of $25 \mathrm{mg} / 1$ to $90 \%$ for the corresponding initial dye concentration of 10 $\mathrm{mg} / \mathrm{l}$. This means that the maximum percentage of dye removal by pomegranate peels occurs at the minimum initial dye concentration. This can be explained by the fact that the dye was adsorbed on the surface of the pomegranate peels, at higher concentrations will have no place to be adsorbed on for the same mass of adsorbent. These results are consistent with the results of previous studies in terms of the effect of initial concentrations of pollutant on the removal efficiency [13].

\section{$I V$. The effect of contact time}

Figures 4 and 5 depict that the longer contact time results in higher removal efficiency of dye. This can be attributed to the long period of contact time between the adsorbent and the wastewater, which will allow an additional amount of dye to be adsorbed on the pomegranate peels. These results correspond with the results of previous continuous flow reactor study [16].

\section{Adsorption Isotherm}

Langmuir [17,18] and Freundlich [19] adsorption models were applied for the results of this study.

Figure 6 illustrates the application of the Langmuir isotherm equation.

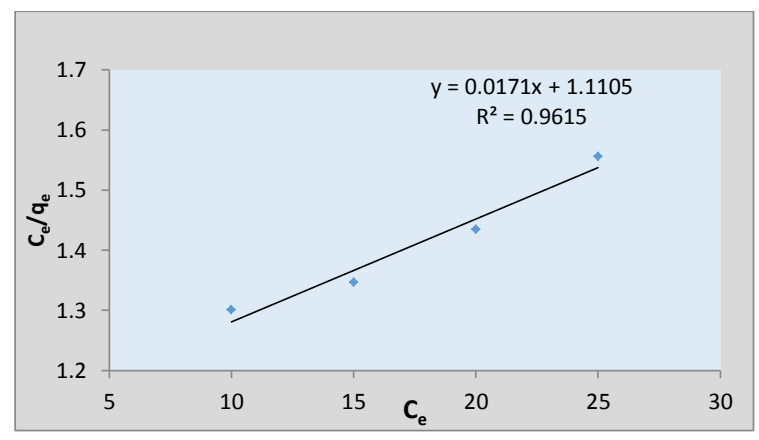

Figure 6: The Langmuir isotherm equation application 
The straight line shown in Figure 6 depicts that the equilibrium data fits with the Langmuir equation. The constants of Langmuir equation (a and b) were calculated from the intercept and the slope of the straight line, respectively $[17,18]$. Table 1 illustrates these results.

Table 1: The constants of Langmuir equation

\begin{tabular}{cccc}
\hline \hline $\mathrm{a}$ & $\mathrm{b}$ & $\mathrm{R}^{2}$ & Correlation equation \\
\hline 1.1 & 0.01 & 0.96 & $\mathrm{Y}=0.017 \mathrm{X}+1.110$ \\
1 & 7 & 1 & \\
\hline
\end{tabular}

Figure 7 describes the application of the Freundlich isotherm equation, in which the straight-line relation shows a good correlation between the data and Freundlich isotherm model. The constants of Freundlich equation are shown in Table 2 calculated as in [19]. Langmuir and Freundlich's equations were both applied perfectly to the data, with Freundlich being more accurate due to its higher correlation coefficient (0.994), for that, it may represent this case of study.

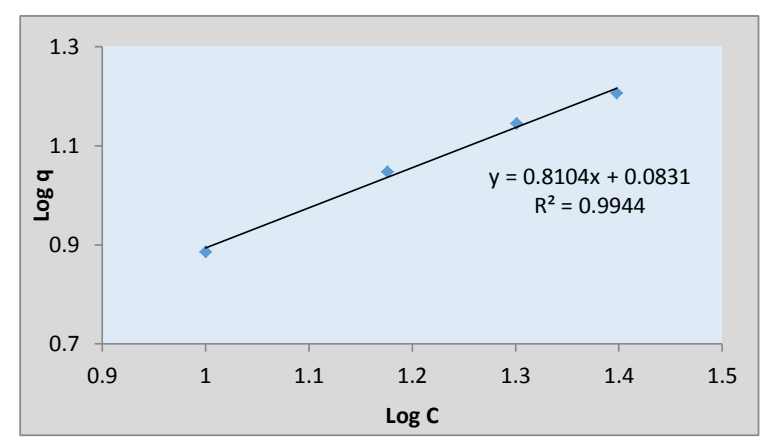

Figure 7: The Freundlich isotherm equation application

Table 2: The constants of Freundlich equation

\begin{tabular}{cccc}
\hline \hline $\mathrm{a}$ & $\mathrm{b}$ & $\mathrm{R}^{2}$ & Correlation equation \\
\hline 0.08 & 0.81 & 0.99 & $\mathrm{Y}=0.810 \mathrm{X}+0.083$ \\
3 & 0 & 4 & \\
\hline
\end{tabular}

\section{Conclusions}

From this study, it can be concluded that pomegranate peels can effectively be used as an adsorbent to remove Cibacron reactive Red FN-R dye from synthetic wastewater. The capacity of removal was increased when keeping the $\mathrm{pH}$ levels within the range of 6 , decreasing each of the flow rate and initial concentration of dye, and increasing the contact time. Both Langmuir and Freundlich isotherm models were well represented in this system, having Freundlich to be with the superior correlation coefficient. The obtained results were compatible with other studies $[13,16]$.

\section{Acknowledgment}

The authors greatly acknowledge the kind support obtained from the Sanitary Laboratory/ Department of Environmental Engineering, Mustansiriyah University, Baghdad, Iraq.

\section{References}

[1] S.N. Al-Hussaini, "Suggested Improvement Techniques for Diyala River Water Opposite AlRustimiyah Sewage Treatment Plants," Ph.D. dissertation, Building and Construction Engineering Department, University of Technology, 2016.

[2] F. Kong, K. Parhiala, S. Wang, and P. Fatehi, "Preparation of cationic softwood kraft lignin and its application in dye removal," European Polymer Journal, Vol. 67, pp. 335-345, 2015.

[3] L.C. Ling, "Treatment of A Reactive Dye, A Disperse Dye, and Their Mixtures Using $\mathrm{H}_{2} \mathrm{O}_{2} /$ Pyridine/Cu (II) System," MSc. Thesis, University of Science, Malaysia, 2009.

[4] A. Wasti and M.A. Awan, "Adsorption of Textile Dye onto Modified Immobilized Activated Alumina," Journal of the Association of Arab Universities for Basic and Applied Sciences, Vol. 20, pp.26-31, 2016.

[5] S. Canzano, P. Iovino, S. Salvestrini and S. Capasso, "Removal of anionic dye Congo red from aqueous solution by row pine and acid treated pine cone powder as adsorbent: Equilibrium, Thermodynamic, Kinetics, Mechanism, and process design," Water Research, Vol. 46, 2012.

[6] A.A. El-Bindary, A.Z. El-Sonbati, A.A. AlSarawy, K.S. Mohamed and M.A. Farid, "Removal of hazardous azopyrazole dye from an aqueous solution using rice straw as waste adsorbent: Kinetic, equilibrium and Thermodynamic studies," Spectrochimica Acta Part A: Molecular and Biomolecular Spectroscopy, Vol. 136, pp. 1842-1849, 2015.

[7] I.H. Dakhil, "A Comparative Study for Removal of Dyes from Textile Effluents by Low-Cost Adsorbents," Mesopotamia Env. Journal, Special Issue A, pp.1-9. 2016.

[8] T.A. Kurniawan, G.Y.S. Chan, W.H. Lo. and S. Babel, "Comparisons of Low-Cost Adsorbents for Treating Wastewaters Laden with Heavy Metals," Science Total Environment, Vol.366, No. 2-3, pp.409426, 2005.

[9] R.F. Gomes, A.C. Neto de Azevedo, A.G.B. Pereira, E.C. Muniz, A.R. Fajardo, and F.H.A. Rodrigues, "Fast dye removal from water by starchbased nanocomposites," Journal of Colloid and Interface Science, Vol. 454, pp. 200-209, 2015.

[10] D.P. Pathak1, S.A. Mandavgane, and B.D. Kulkarni, "Characterizing fruit and vegetable peels as Bioadsorbents," Current Science, Vol.110, No. 11, 2016. 
[11] M. Dehvair, M.T.Ghaneian, A. Ebrahimi, R. Jamshidi And M. Mootab, "Removal of Reactive Blue 19 Dye from Textile Wastewater by Pomegranate Seed Powder," International Journal of Environmental Health Engineering, Vol.4, No.4, pp.1-9 2015.

[12] M.A. Ahmad, N.A. Ahmad Puad, O.S. Bello, "Kinetic, equilibrium and thermodynamic studies of synthetic dye removal using pomegranate peel activated carbon prepared by microwave-induced $\mathrm{KOH}$ activation," Water Resour. Ind., Vol. 6, pp. 1835, 2014.

[13] S. Ben-Ali, I. Jaouali, S. Souissi-Najar, and A. Ouederni, "Characterization and adsorption capacity of raw pomegranate peel biosorbent for copper removal," Journal of Cleaner Production, Vol.142, pp. 38093821, 2017.

[14] M. Abedi, M.H. Salmani, and S.A. Mozaffari, "Adsorption of $\mathrm{Cd}$ ions from aqueous solutions by iron modified pomegranate peel carbons: kinetic and thermodynamic studies," Int. J. Environ. Sci. Technol, Vol. 13, pp.2045-2056, 2016, DOI 10.1007/s13762016-1002-7.

[15] F. Güzel, O. Aksoy and G. Akkaya, "Application of pomegranate (punica granatum) pulp as a new biosorbent for the removal of a model basic dye (methylene blue)," World Appl. Sci. J., Vol. 20, pp. 965-975, 2012.

[16] Sh. M. Goodman, R. Bura and A. B. Dichiara, "Facile Impregnation of Graphene into Porous Wood Filters for the Dynamic Removal and Recovery of Dyes from Aqueous Solutions," ACS Appl. Nano Mater., 2018, DOI: 10.1021/acsanm.8b01275.

[17] L. Langmuir, "Chemical reaction at low temperature," J. Amer Chem. Soc., Vol. 37, 1915.

[18] L. Langmuir, "The Adsorption of gases on plane surface of glass, mica and platinum," J. Amer Chem. Soc., Vol. 40, 1918.

[19] H. Freundlich, "Colloid and Capillary Chemistry," Methuen, London, 1926. 